\title{
Notes on the new economic paradigm: encouraging debate
}

\begin{abstract}
At the end of the 21 st century, even if the capitalist mode of production persists, a new economic paradigm has been structured, it is linked to concepts such as globalization, innovation, networks, technologies, territory and knowledge and learning. Concepts that circulate in literature, but rarely appear articulated. Communication is a theoretical exercise that seeks to articulate these concepts and from foreign referents, to foment the debate on the paths to be covered by Brazil in this century. There is a strong concern with these issues in the central countries and much, captained by economic geography, it is up to the Brazilian geography also to enter this discussion and for this reason this communication is justified.
\end{abstract}

Volume 2 Issue 3 - 2018

\author{
Giovana Mendes De Oliveira \\ Department of Geography, Federal University of Pelotas, Brazil
}

Correspondence: Giovana Mendes De Oliveira, Department of Geography, Federal University of Pelotas, Brazil, Tel (53) 32845523 Email Geoliveira.ufpel@gmail.com

Received: February 27, 2018 | Published: May |4, 2018

\section{Introduction}

Communication is anchored in the discussion of the economic paradigm of the $21^{\text {st }}$ century, which values the competitive advantages that are based on the information society, knowledge and learning. The term "new paradigm" is referred to because the globalization under way, with the help of digital technologies, produces amazing rhythms of innovation and, in this way, the structure of work, of companies and of the State itself, needs to act differently to remain within the capitalist market. And this is true in both central and semi-peripheral countries. It is up to the researchers to understand this process, to propose strategies that can be of adoption of the prevailing way or the construction of an alternative way. This study is a theoretical discussion about the key concept to understand the new economic paradigm and its interconnection. It discusses globalization, innovation, territory, technologies and knowledge and learning, seeking to clarify the elements of this new paradigm and with this help in the debate about the future of Brazil, which has not been able to structure an innovation system and has not supported another perspective of socioeconomic.

\section{Methodology}

The proposal presented is a theoretical revision from the foreign literature. In particular teachers Castells, Lundvall, Boschamann, and Asheim.

\section{Results and Discussion}

Globalization is a multidimensional process, yet it can be better understood by its economic dimension, it is the center of the process. A global economy is an economy whose main activities function as a real-time unit on a planetary scale; ${ }^{1}$ thus, the globalized economy is a threshold of the capitalist economy, in which Fordist practices are no longer relevant and are adopted flexibly. This new stage of the economy requires competitive economies and for this they need to seek innovation. According to Poter, ${ }^{2}$ economies with low productivity show little competitiveness and the greater competition comes from imports and involves imitation, price is the only competitive variable, and companies recurrently assure prices with low wages, in this way the competition involves a investment. In the current paradigm the rivalry must change from low wages to low total cost, which requires updating and pursuit of efficiency, ranging from product manufacturing to delivery service. This means that competitiveness must also evolve beyond cost to include differentiation. In short, the new global paradigm has as its imperative that competition should shift from imitation to innovation.

Innovation is not just new ideas; they are ideas that can be products for the market. If an innovation cannot generate a product to be marketed, or a process that improves the efficiency of a service or even facilitates the purchase of a product, this is not innovation. And for innovation to be effective it needs to be diffused, "without diffusion an innovation has no economic impact. The minimum requirement for a change in the company's products or functions to be considered an innovation is that it is new (or significantly improved) for the company. "(OSLO, 1997, p24). There are different types of innovation, the radicals that effectively generate new products, and the incremental ones that are product improvements. Innovation is not a novelty in the literature, Schumpeter ${ }^{3}$ in the 1930s alluded to technological innovations as the cause of changing economic cycles, placing audacious entrepreneurs the merit of accomplishing new things that would revolutionize the market. However, the innovation advocated today by the economy to attribute competitiveness is linked to a complex system. For innovation to take place, actors and their territories are key. The first are companies, states and universities and even the users themselves of the news; the second is the product of the relationship between power, actors and resources that will foster the formation of the innovation ecosystem. And here we can launch the concept of synergy, considered here as a movement between actors that promotes cooperation, cohesion, allowing an operation of associated people. This territory in which people promote synergy equals an ecosystem.

Among the actors are small and medium-sized companies, but mainly the large international conglomerates are at the tip of this process, they, with their own research and development laboratories have revolutionized the market, acting in various mergers and acquisitions has concentrated production and profitability. These companies are important for fragile economies, those that do not have endogenous power for innovative development, but of course, it is rare for a regional development theory to bet on them as the only way to generate innovation and competitiveness. From these 
statements, the question is how territories in peripheral countries can innovate, and how they manage to do so. This innovation needs a lot of networks, which can be defined as a set of interconnected nodes, forming a mesh, forming a territory. It can have a hierarchy and a center; it is not highlighted, giving the impression of nonexistent The relationships between the nodes are asymmetrical, but all are necessary for the functioning of the network, whether it is set up for the circulation of money, information, technology, images, goods, services or persons. Being networked means increasing the chances of competitiveness, of employment, being off the grid, that is, off, may mean the chances disappear, as everything goes around a global network of interactive networks. Networks are the right organization for the relentless adaptation and extreme flexibility required by an interconnected global economy. Of course, networks have always existed in human organization, but now they alone have become the most powerful way to organize society. The strength of the networks is flexibility, decentralization capacity, adaptation to new tasks, the network is at the same time centralized and decentralized. It can be coordinated without a center, and with this instead of instructions, we have interactions. Multinational corporations function internally as decentralized networks, whose elements receive considerable autonomy; each element of these networks is usually part of other networks, some of them formed by small and medium-sized auxiliary companies; other networks attach themselves to other large corporations around specific projects and tasks, often with no synchronization of time and space. But it is not only multinational companies, the network are part of the learning and creation process, as will be presented below, certain types of knowledge cannot advance without being in networks.

Globalization, innovation and networking could only exist in the way they are today from technological development, which is possible to be called digitization. Digital technologies from a binary code, have managed to revolutionize our technical objects and created another hundred of them, the computer and the internet are motors of this technology, but they go far. However, the elementary factor of understanding of this issue is the possibility of human brain power that this digitization provided. Ideas that before being put into practices should be tested with expensive prototypes, today with the ease of the virtual world it is already possible to be mounted and tested virtually; endless calculations are perfectly solved with supercomputers; Delicate and detailed training is also possible through virtualization. The digital world has accelerated our ability to think and store knowledge by allowing our ideas to become realities quickly but also quickly become obsolete. Thus, the important feature of the present developmental phase is the high rate of change in skill requirements. This implies that all categories of skills and abilities must be renewed from time to time, that is, organizations have to continually develop new competencies. ${ }^{4}$ This leads to the need to build a learning economy. A company, a territory cannot live on novelties occurred in past years, because on the other side of the world may already have been invented something that completely ends with its activity. The main reason why learning has to become more important is linked to the dialectic between learning and changing. Rapid change implies a need for those involved in learning to make rapid learnings in order to change the environment and other people. What we have then is a learningbased economy to compete, which leads us more and more to trying to understand how learning happens and how territories influence it.
Learning and knowledge being central transferred the attention of theorists to the division of tacit and codified knowledge. The codification of knowledge implies that such knowledge is transformed into information that can easily be transmitted through an information infrastructure, namely virtual or physical means. Coded knowledge can usually be transferred over long distances and across organizational boundaries. ${ }^{4}$ The increasing agility of transmission of knowledge encoded by the digital pathways makes it capable of circulating rapidly throughout the world, in a lawful or illicit manner. With this, the rate of change accelerates. This makes it less attractive to code knowledge since it makes innovation faster, and obsolete. However, it is important to know that knowledge also comes in tacitly. Tacit knowledge is knowledge that cannot be easily transferred because it is centered on the person or group that produces it, it is linked to knowhow, but not clear enough for those who are about to code. Lundavall ${ }^{4}$ points out as an important type of tacit knowledge the skill. Another important type of tacit knowledge is shared by beliefs and modes of interpretation. This implies that it cannot be sold and bought in the market and that its transference is extremely sensitive to the social context. The recognition of the need for these two types of knowledge allows us to think about the importance of the territory formed to allow the synergy between the actors to percolate both tacit knowledge and codified knowledge to produce innovation. In this sense proximity is important because it would allow the exchange of this tacit and codified knowledge.

Boschamann ${ }^{5}$ goes further in defining the proximity, according to it can be classified in: cognitive that refers to the extent to which two actors share the same knowledge base; social, relationship that is associated with personal relationships between actors as a result of past collaborations; institutional, when actors operate under the same set of rules and incentives, for example, when co-located in the same country or operating in the same subsystem, such as industry or government. And the organizational proximity refers to the association with the same organizational entity, as is the case, for example, of two branches of the same company. No less important to discuss knowledge, and therefore innovation is the discussion of Asheim ${ }^{6}$ approach is based on the definition of three types of knowledge relevant to innovation: analytical, synthetic and symbolic knowledge. Analytical knowledge is largely based on scientific knowledge created through deductive processes and formal models. Much of this knowledge is codified, for example, in patents or research publications. Synthetic knowledge is applied, directed to problem solving. It is created through interactive processes involving clients or suppliers, in which case tacit knowledge plays an important role. Symbolic knowledge represents the ability to understand and interpret the habits and norms of popular culture. ${ }^{7}$ The innovations result from the creation of meaning and desire through the generation of new projects, aesthetic and intangible. This type of knowledge exhibits a high cultural insertion and is usually created through exchange in informal and professional communities, often within a specific context. Depending on the activity of the company it will need different proximity, some more connected to external networks, others more connected to the face-to-face and others linked to the buzz. ${ }^{8}$

Face-to-face reflects the feeling that two or more people are physically co-present in a way that allows mutual visual and physical contact, is associated with a multidimensional communication process, 
is an efficient way to exchange tacit knowledge, but also codifiable. Tinnitus is the idea of noise echoing by sounds that are evoked by many. Where much happens, information circulates if networks are made, ${ }^{9}$ where I quickly have the perception of the news or what needs to be created. Thus, buzzing and face-to-face enable innovation and refer back to the territory. In other words, they are important elements for the actors who want to organize their territories for innovation. Among the territories that would be more competitive are the metropoles, because in it we find the bubble, in them are several actors who have knowledge, capital that motivates the face-to-face. In this way, it can be seen that the metropoles in the economy of knowledge and learning become relevant, which allows us to speak in turn about the concentration and / or aggre-gation of the agglomeration in the metropolis. Everything indicates that globalization forms a territory in network, and each point of this network are competitive territories, network that leaves many other territories. This makes sense to the concern of some authors with territorial and social cohesion and smat especilization, which are also adopted by the European Union. ${ }^{10}$ The first one admits that some territories did not penetrate into the current economic logic, necessitating organization for this, since their departure from the paradigm means social problems, and in this sense the need to seek territorial cohesion. The second point is that for the entry into the new paradigm it needs planning based on innovation and the characteristics of each territory. ${ }^{11}$

\section{Conclusion}

The theoretical exercise presents an interconnection between the concepts of globalization, innovation, networks, territory, economy and learning. In doing so it is evident that we live within an informational technical-scientific milieu and how much work and the worker need to change to meet this paradigm. Specifically we know that Brazil is without a project for the future and it is up to us researchers to discuss the alternatives followed by the central countries and decide which way to go. Finally, the communication presents theoretical questions to open a debate.

\section{Acknowledgments}

None.

\section{Conflict of interest}

The author declares that there is no conlict of interest.

\section{References}

1. Castells Manuel. A sociedade em rede. São Paulo: Paz e Terra; 1999. $34 \mathrm{p}$.

2. Porter Michael E. Clusters and Competition: New Agendas for Companies, Governments, and Institutions. USA: Harvard Business School Working Paper; 1998:98-080.

3. Schumpeter JA. Teoria do desenvolvimento econômico: uma investigação sobre lucros, capital, crédito, juro e o ciclo econômico. São Paulo: Nova Cultural; 1930. 228 p.

4. Lundvall Bengt Ake, Borrás Susana. The globalising learning economy: Implications for in inovation policy. Luxembourg: Office for Official Publications of the European Communities; 1998. 175 p.

5. Boschma Ron, Gianelle Carlo. Regional Branching and Smart Specialisation Policy. Luxembourg: Publications Office of the European Union; 2014. 1-28 p.

6. Asheim Björn, Grillitsch Markus, Trippl Michaela. Regional Innovation Systems: Past-Presence-Future. In: Doloreux D, Shearmur R, editors. Handbook on the Geography of Innovation. UK: Edward Elgar; 2016. 45-62 p

7. Foray Dominique, John G, Beldarrain XG, et al. Guide to Research and innovation Strategies for Smart Specialisation (RIS 3). Europe: European Commission; 2012. 126 p.

8. Mccann Philip, Ortega Argilés Raquel. Smart Specialization, Regional Growth and Applications to European Union Cohesion Policy. Regional Studies. 2015;49(8):1291-1302.

9. Clélio CD, Lemos Mauro. Economia e território. Belo Horizonte: UFMG (Universidade Federal de Minas Gerais); 2005. 21-56 p.

10. Broekel Tom, Boschma Ron. The cognitive and geographical structure of knowledge links and how they influence firms' innovation performance. Regional Statistics. 2016;6(2):3-26.

11. Martin Romanm, Moodysson Jerker. Comparing knowledge bases: on the geography and organization of knowledge sourcing in the regional innovation system of Scania, Sweden. European Urban and Regional Studies. 2013;20(2):170-187. 